$$
\text { DUE/ER/URIOA-DTP }
$$

\title{
Catalytic Oxidation of Secondary Alcohols
}

DOE/ER/45120--T2

Robert L. Augustine and Lisa K. Doyle

DE93 002765

\author{
Department of Chemistry, Seton Hall University, South Orange, NJ 07079
}

\section{Abstract}

The dioxygen oxidation of alcohols over platinum catalysts has been known for a long time. While of potential importance in synthetic procedures, this process has never found extensive use except in carbohydrate oxidations. Some reasons for this is the fact that this reaction only appears to work well in an aqueous medium in the presence of rather large amounts of a Pt black catalyst. The results obtained here show that supported Pt catalysts can be used to promote this oxidation in organic solvents provided a small amount of water is added to the reaction medium. It was also established that the reaction takes place on the more coordinately unsaturated corner atoms on the Pt surface.

\section{Introduction}

The platinum catalyzed oxidation of alcohols with dioxygen has been known for some time [1]. This reaction, though, has found only iimited utility in synthetic procedures as it is commonly run in aqueous medium using a rather large quantity of reduced $\mathrm{PtO}_{2}$ as the catalyst. This procedure is most commonly used for the selective oxidation of sugars [2] and other polyhydroxylic compounds [1] but only limited data are available describing its use for the oxidation of alcohols in non-aqueous media. A recent study has estatlished that supported $\mathrm{Pt}$ catalysts can be effectively used in place of the reduced $\mathrm{PtO}$, [3]. $\mathrm{Pt} / \mathrm{SiO}$, was reasonably effective in promoting the dioxygen oxidation of 2-propanol in water. $\mathrm{Pt} / \mathrm{C}$ and $\mathrm{Pt} / \mathrm{Al}_{2} \mathrm{O}_{3}$ were less active for this reaction. It was noted that these supported catalysts were prone ${ }^{3}$ deactivation during the reaction. It was thought that this deactivation was the result of either the interaction of the metal with some very strongly adsorbed minor reaction product or that the surface of the metal crystallites on the support was being oxidized by the dioxygen in the reaction medium [3].

It was also shown that the reaction proceeded more readily over catalysts having lower dispersions. Because of the catalyst deactivation it is generally considered that the decreased activity of the more highly dispersed catalysts is the result of a more facile oxidation of the smaller Pt particles present in such catalysts [3]. There is, though, another possible explanation. This oxidation could be taking place on ensembles of face atoms on the surface of the Pt crystallites and the larger metal particles associated with catalysts of low dispersion would have more such active sites available for reaction.

Because of the potential utility of this reaction in synthetic processes the present investigation was initiated with the aim of determining both the nature of the active sites on the catalyst which promote the oxidation and the possible reasons why organic solvents appear to be incompatible with the reaction.

\section{Identification of Active Sites}

The Single Turnover (STO) reaction sequence has been established as a means of measuring the quantities of a number of different type, of active sites present on supported metal catalysts [4]. With this procedure it is possible, to determine the site densities of five different types of sites on the catalyst surface. Three of these, the ${ }^{3}{ }_{1}, M_{2}$ and ${ }^{3} \mathbf{M}$, are corner atoms which are involved in the saturation of double bonds [4], the dehydrogenation of cyclohexane [5], and the oxidation of $\mathrm{CO}[4,6]$. Another, the $\mathrm{M}$, is an edge atom which

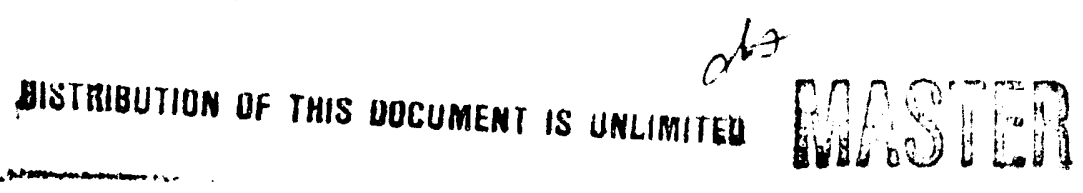




\section{DISCLAIMER}

This report was prepared as an account of work sponsored by an agency of the United States Government. Neither the United States Government nor any agency thereof, nor any of their employees, makes any warranty, express or implied, or assumes any legal liability or responsibility for the accuracy, completeness, or usefulness of any information, apparatus, product, or process disclosed, or represents that its use would not infringe privately owned rights. Reference herein to any specific commercial product, process, or service by trade name, trademark, manufacturer, or otherwise does not necessarily constitute or imply its endorsement, recommendation, or favoring by the United States Government or any agency thereof. The views and opinions of authors expressed herein do not necessarily state or reflect those of the United States Government or any agency thereof. 


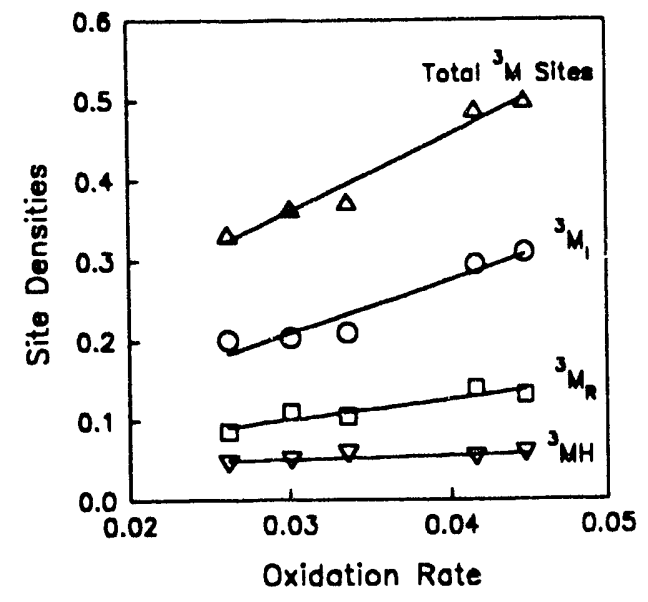

Fig. 1 Relationship between the ${ }^{3} \mathrm{M}$ site densities and the rates of oxidation of 2-propanol over a series of STO characterized Pt/CFG catalysts. promotes doyble bond isomerization and the last, the $M$ or face atom, does not appear to take part in an alkene hydrogenation reaction at all. To determine the nature of the active site involved in a specific reaction all that need be done is to run the reaction over a series of STO characterized catalysts and look for a relationship between specific site densities and the reaction rates. If the $\mathrm{Pt}$ catalyzed alcohol oxidation were promoted by ensembles of face atoms then there would be a correlation between the rates of the reactions run over several catalysts and the $M$ site densities. If it were taking place on the more unsaturated corner atoms then the rates would be related to the amounts of the ${ }^{3} \mathrm{M}$ sites present on each catalyst.

To clarify this matter the oxidation of 2-propanol in water was run over a series of STO characterized Pt/CPG (Controlled Pore Glass) catalysts with the rate determined for the initial $20 \%$ of the reaction. In Fig. 1 is shown the relationship between the reaction rates and the $\mathrm{M}$ site densities for these catalysts. No correlation was observed between the reaction rates and the site densities for the $\mathbf{M}$ and/or $M$ sites. These results indicate that this oxidation is taking place on the more highly unsaturated corner atoms on these catalysts and not on ensembles of face atoms.

$$
\begin{aligned}
& \text { Reaction TOF }=A *\left[{ }^{3} \mathrm{M}_{\mathrm{I}}\right]+\mathrm{B} *\left[{ }^{3} \mathrm{M}_{\mathrm{R}}\right]+\mathrm{C} *\left[{ }^{3} \mathrm{MH}\right] \\
& \text { (moles } \mathrm{O}_{2} / \text { mole Pt } / \mathrm{min} \text { ) }
\end{aligned}
$$

Since the overall reaction turnover frequency (TOF) is the sum of the individual site reactivities as shown in eq. 1 [7], these reaction data can be used to evaluate the activities of each type of ${ }^{3} \mathrm{M}$ site present on these catalysts. The ${ }^{3} \mathrm{M}$ site densities for each catalyst and the observed TOF for the oxidation using it were placed into eq. 1 and the values for the specific site TOF's, A, B and C were calculated from this series of simultneous equations. This gave a site TOF for the ${ }^{3} \mathrm{M}_{\mathrm{I}}$ sites, A in eq. 1 , of 0.078 moles $\mathrm{O}_{2} /$ mole site $/ \mathrm{min}$. That for the ${ }^{3} \mathrm{M}_{\mathrm{R}}$ sites was 0.132 and that for the ${ }^{3} \mathrm{MH}$ sites was 0.084 . Table 1 lists the observed reaction TOF's along with those calculated using eq. 1 with these specific site TOF values and the site densities for each catalyst.

\section{Table 1}

Observed and Calculated TOF Values (moles $\mathrm{O}_{2} /$ mole Pt / min) for 2-Propanol Oxidations Run Over a Series of PU/CPG Catalysts

\begin{tabular}{ccc}
\hline Catalyst & $\begin{array}{c}\text { Observed } \\
\text { TOF }\end{array}$ & $\begin{array}{c}\text { Calculated } \\
\text { TOF }\end{array}$ \\
\hline I & 0.0448 & 0.0424 \\
II & 0.0416 & 0.0418 \\
III & 0.0336 & 0.0326 \\
IV & 0.0301 & 0.0318 \\
V & 0.0262 & 0.0292 \\
\hline
\end{tabular}




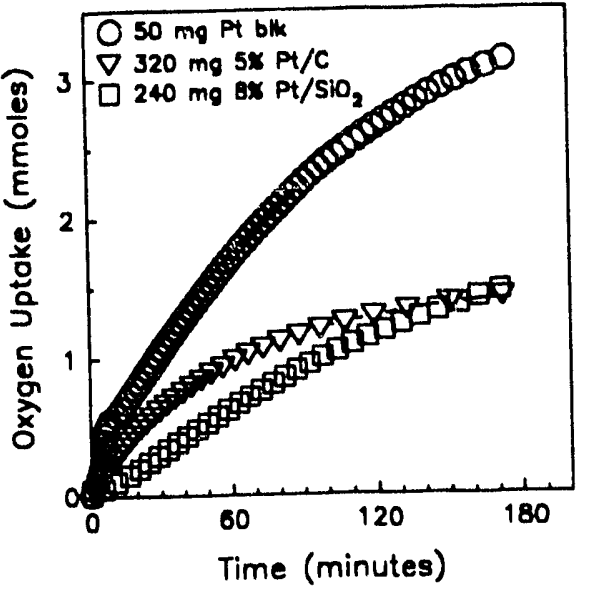

Fig. 2 Rate of oxidation of 2propanol run in heptane over Pt Catalysts.

\section{Solvent Studies}

To examine whether non-aqueous media could be used for this reaction, the oxidation of 2-propanol was run in a number of solvents over Pt black which was obtained by the reduction of $\mathrm{PtO}_{2}$, as well as with $5 \% \mathrm{Pt} / \mathrm{C}$ and $8 \% \quad \mathrm{Pt} / \mathrm{SiO}_{2}$. Fig. 2 illustrates the extent of $\mathrm{O}_{2}$ uptake when this reaction was run in heptane over each of these catalysts. With the Pt black the reaction proceeded to completion even though the water produced by the oxidation caused the catalyst to clump up during the reaction. With Pt/C clumping was also evident but the reaction only went to about $50 \%$ completion. The $\mathrm{Pt} / \mathrm{SiO}_{2}$ catalyst did not promote the reaction at all if pure heptane, water had to be added to the reaction mixture before the reaction would take place. As stated in the literature [3], the use of $\mathrm{Pt} / \mathrm{SiO}_{2}$ catalysts did not give reproducible results so most of the solvent evaluation work was done using a commercial 5\% Pt/C catalyst.

In Table 2 are listed the TOF's and the percent completion observed for a series of 2 propanol oxidations run over the $\mathrm{Pt} / \mathrm{C}$ catalyst in a variety of solvents. These data show that the presence of water in the reaction medium is essential for obtaining reasonable reaction rates and conversions. This is true even though the catalyst tends to aggiomerate somewhat in these partially aqueous systems. Those reactions run in the absence of water take place at a very slow rate with, at most, only about a $50 \%$ conversion of the alcohol observed before the reaction stopped. Those run in the presence of water, except for the $\mathrm{MeOAc} / \mathrm{H}_{2} \mathrm{O}$ mixture, proceed more rapidly and give a near theoretical conversion. MeOAc itself is not as good a solvent for this reaction as EtOAc presumably because of the increased solubility of water in MeOAc. This apparently removes the water from the surface of the catalyst, a factor which seems to be essential for the success of the reaction. The

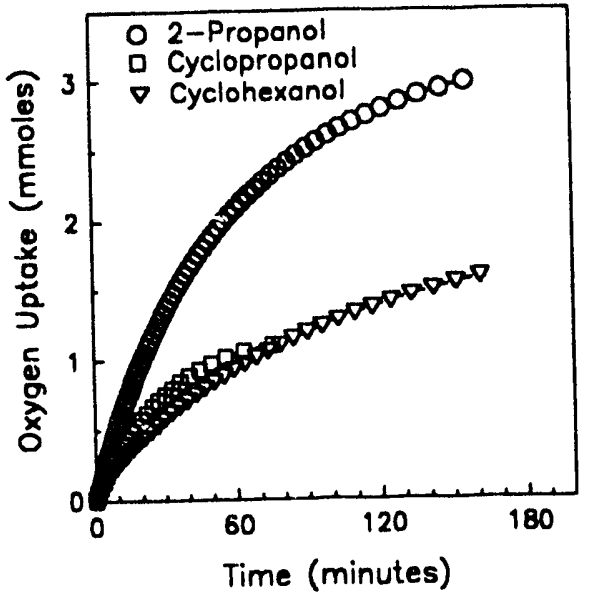

Fig. 3 Oxidation of 2-propanol, cyclohexanol and cyclopentanol over $5 \% \mathrm{Pt} / \mathrm{C}$ in heptane-MeOAcwater. hydrophobicity of $\mathrm{Pt} / \mathrm{C}$ permits the use of oniy a small amount of water to promote the oxidation. With $\mathrm{Pt} / \mathrm{SiO}$, though, the $\mathrm{SiO}_{2}$ is quite hydrophilic and much more water is needed.

For synthetic purposes the use of the heptane-MeOAc-water mixture in the ratios shown in Table 2 are recommended. For those compounds which are not soluble in a nonpolar medium, the EtOAc-water combination can serve as a reasonable substitute. Fig. 3 shows the extent of oxygen uptake for the oxidation of cyclohexanol and cyclopentanol over $\mathrm{Pt} / \mathrm{C}$ in the heptane-MeOAc-water solvent mixture. 


\section{Table 2}

Influence of Solvent Composition on 2-Propanol Oxidation over 5\% Pt/Ca

\begin{tabular}{|c|c|c|c|c|c|}
\hline \multicolumn{4}{|c|}{ Volume (mI) } & \multirow[t]{2}{*}{ Rate b } & \multirow{2}{*}{$\begin{array}{l}\text { \% Theo. } \\
\text { Uptake }\end{array}$} \\
\hline MeOAC & EtOAc & Heptane & Water & & \\
\hline $\begin{array}{l}15.0 \\
12.0 \\
7.5 \\
2.5 \\
2.5\end{array}$ & $\begin{array}{l}15.0 \\
15.0 \\
2.5 \\
2.5\end{array}$ & $\begin{array}{l}7.5 \\
12.5 \\
12.5\end{array}$ & $\begin{array}{l}3.0 \\
0.5 \\
0.5 \\
0.5\end{array}$ & $\begin{array}{c}0.00^{d} \\
0.08 \\
0.03 \\
0.07 \\
0.94 \\
0.22 \\
0.62 \\
0.37 \\
0.65\end{array}$ & $\begin{array}{c}50 \\
20 \\
50 \\
100 \\
50 \\
90 \\
50 \\
90 \\
\end{array}$ \\
\hline
\end{tabular}

a $0.6 \mathrm{ml}$ 2-propanol, $320 \mathrm{mg} 5 \% \mathrm{Pt} / \mathrm{C}, 30^{\circ} \mathrm{C}$.

b mole o / mole Pt / min.

c The theoretical oxygen uptake is about $3.5 \mathrm{mmoles}$

d No reaction observed.

e The minimum amount of water needed for the reaction to proceed in MeOAc.

\section{Acknowledgment}

This work was supported by Grant DE-FG0284ER45120 from the U. S. Department of Energy, Office of Basic Energy Science.

\section{References}

1. K. Heyns and H. Paulsen, Newer Methods of Preparative Organic Chemistry, Vol. II, Academic Press, New York, p 303.

2. J. M. Dirkx, J. Catal., 67, 1 (1981).

3. J. W. Nicolette and G. M. Whitesides, J. Phys. Chem., 93, 759 (1989).

4. R. L. Augustine, D. R. Baum, K. G. High, L. S. Szivos and S. T. O'Leary, J. Catal., 127, 675 (1991).

5. R. L. Augustine and M. M. Thompson, J. Org. Chem., 52, 1911 (1987).

6. N. W. Cant, J. Catal., 62, 173 (1980).

7. R. L. Augustine, M. M. Thompson and M. A. Doran, J. Chem. Soc., Chem. Commun., 1173 (1987). 

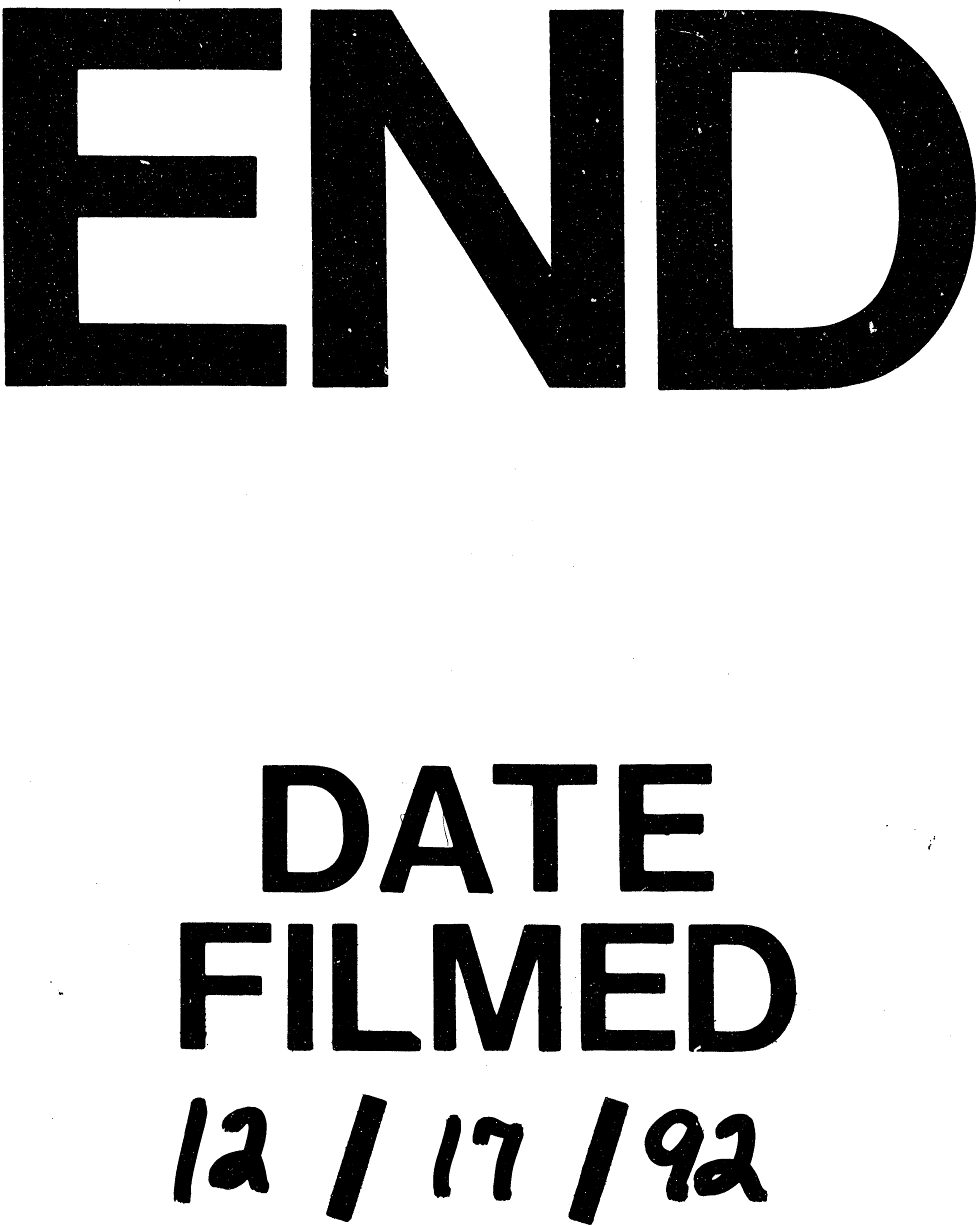
